\title{
Time Course of Recovery of Extracellular Dopamine following Partial Damage to the Nigrostriatal Dopamine System
}

\author{
Terry E. Robinson, ${ }^{1}$ Zoltan Mocsary, ${ }^{1}$ Dianne M. Camp, ${ }^{1}$ and lan Q. Whishaw ${ }^{2}$ \\ 'Department of Psychology and Neuroscience Program, The University of Michigan, Ann Arbor, Michigan 48104-1687 and \\ 'Department of Psychology, University of Lethbridge, Lethbridge AB, Canada
}

\begin{abstract}
Partial damage to the nigrostriatal dopamine (DA) system can produce severe behavioral deficits, from which animals gradually recover. Although the compensatory neuroadaptations that contribute to recovery of function have received considerable attention, the exact role of presynaptic versus postsynaptic contributions remains unclear. For example, it has been suggested that presynaptic adaptations may not be sufficient to account for recovery of function, because compensatory increases in DA biosynthesis, metabolism, and release are maximal within $3 \mathrm{~d}$ following a unilateral 6-hydroxydopamine (6-OHDA) lesion, before behavioral recovery is complete. The purpose of this study was to examine another presynaptic adaptation, the normalization of extracellular DA. If this is also complete within $3 \mathrm{~d}$ postlesion, it, too, would be insufficient to account for the protracted time course of behavioral recovery. But if the normalization of extracellular DA proceeds more gradually, it could potentially account for the time course behavioral recovery. To address this issue, the extracellular concentration of striatal DA ipsilateral and contralateral to a unilateral 6-OHDA lesion was estimated with microdialysis, either $4 \mathrm{~d}$ or 3-4 weeks following the lesion. After estimating the basal extracellular concentration of DA, the ability to increase DA release further was assessed by administering an amphetamine challenge. It was found that in animals with a 6-OHDA lesion, the concentration of DA in dialysate was higher than would be predicted by the extent of DA denervation. Furthermore, in groups matched for lesion size, extracellular DA was significantly higher 3-4 weeks following a 6-OHDA lesion than $4 \mathrm{~d}$ following the lesion. These findings suggest that the normalization of extracellular DA may be a relatively gradual process, and therefore may be sufficient to account for the protracted time course of behavioral recovery.
\end{abstract}

[Key words: striatum, caudate nucleus, microdialysis, substantia nigra, 6-hydroxydopamine, recovery of function]

Complete ( $>95 \%$ ) destruction of the nigrostriatal dopamine (DA) system produces a variety of motor, sensory, and cognitive deficits from which animals never recover; that is, there is a per-

Received July 12, 1993; accepted Oct. 19, 1993.

This research was supported by a grant to T.E.R. from the National Parkinson Foundation (USA) and to I.Q.W. from the Medical Research Council of Canada.

Correspondence should be addressed to Dr. Terry E. Robinson, Neuroscience Laboratory Building, The University of Michigan, 1103 East Huron Street, Ann Arbor, MI 48104-1687.

Copyright $\odot 1994$ Society for Neuroscience 0270-6474/94/142687-10\$05.00/0 manent loss of function (for reviews, see Stricker and Zigmond, 1976; Marshall, 1985; Stricker and Zigmond, 1986; Robinson et al., 1990a). Animals with extensive but partial depletion (80$95 \%$ ) of striatal DA initially show severe behavioral deficits, and the magnitude of behavioral dysfunction is positively correlated with the depletion of striatal DA in postmortem tissue and cell loss in the substantia nigra (Lees et al., 1985), but most of these animals eventually regain many of their behavioral capacities; that is, they show recovery of function (Zigmond and Stricker, 1973; Marshall et al., 1974; Marshall, 1979). Following even less severe damage to DA systems $(<80 \%)$, there is considerable sparing of function. That is, the more salient behavioral deficits associated with a loss of the DA input to the striatum are not seen (Stricker and Zigmond, 1974). It is established, therefore, that the nigrostriatal DA system is necessary for normal behavior, but only $10-20 \%$ of the DA input to the striatum seems to be required to maintain relatively normal function.

Behavioral studies have generated considerable interest in the nature of neuroadaptations responsible for recovery and sparing of function, and a number of compensatory neuroadaptations have been identified in DA systems (for reviews, see Stricker and Zigmond, 1976; Marshall, 1985; Robinson et al., 1990a; Zigmond et al., 1990b). Following even moderate damage, presynaptic changes include an increase in the synthesis, metabolism, and fractional release of DA in the remaining DA terminals. Presumably, these kinds of presynaptic adaptations contribute to the ability of recovered animals to maintain a relatively normal basal extracellular concentration of DA in the striatum, at least until the lesion becomes very large (Robinson and Whishaw, 1988; Zhang et al., 1988; Touchet and Bennett, 1989; Abercrombie et al., 1990; Castañeda et al., 1990; Robinson et al., 1990b; Parsons et al., 1991). If lesion size exceeds $80-90 \%$, there are also postsynaptic adaptations, including postsynaptic DA receptor supersensitivity (Ungerstedt, $1971 \mathrm{~b}$; Mishra et al., 1974; Creese et al., 1977; Neve et al., 1982).

Despite a considerable amount of research on compensatory presynaptic and postsynaptic adaptations, their relative roles in mediating recovery of function are not yet clear. Presynaptic adaptations in residual DA neurons, which lead to the normalization of extracellular DA, are thought to be necessary for recovery of function because (1) if over $95 \%$ of the DA input to the striatum is lost, animals do not show behavioral recovery, despite postsynaptic receptor supersensitivity (Stricker and Zigmond, 1976; Marshall, 1979; Marshall, 1984); (2) there is a marked drop in extracellular DA in animals with a greater than 95\% lesion (Castañeda et al., 1990); and (3) deficits can be reinstated in recovered animals by treatments that further compromise DA activity (Stricker and Zigmond, 1976; Stricker and 
Zigmond, 1986). Nevertheless, presynaptic adaptations seem not to be sufficient to mediate recovery of function, because many are already maximal well before recovery is complete (Marshall, 1984). For example, Altar et al. (1987) reported that following a unilateral 6-hydroxydopamine (6-OHDA) lesion, compensatory increases in DA biosynthesis and metabolism are maximal within $3 \mathrm{~d}$, even though considerable recovery of sensorimotor function takes place after this time. On the basis of these studies, Altar et al. (1987) suggested that presynaptic adaptations may be insufficient to mediate recovery of function, because they do not account for the protracted time course of behavioral recovery.

The ability of animals with a partial 6-OHDA lesion to maintain a relatively normal extracellular concentration of DA may be more relevant for behavioral recovery (Robinson et al., 1990a), however, and this was not quantified by Altar et al. (1987). They used postmortem measures of DA synthesis and metabolism (e.g., DOPAC:DA ratios), which can be unreliable indices of DA release and extracellular DA (Commissiong, 1985). Although they also quantified 3-methoxytyramine (3-MT), which in intact animals is thought to be a much more reliable indicator of DA release (Wood and Altar, 1988), 3-MT may not reflect the extracellular concentration of DA. This is because the extracellular concentration of DA is due to complex interactions between DA release, DA degradation, and DA clearance (Wightman and Zimmerman, 1990; Parsons et al., 1991; Menacherry et al., 1992).

The purpose of this experiment, therefore, was to use in vivo microdialysis (Ungerstedt and Hallström, 1987) to determine if the normalization of extracellular DA is essentially complete within $4 \mathrm{~d}$ following a unilateral 6-OHDA lesion of the nigrostriatal DA system. If so, the concentration of DA in striatal dialysate collected from the lesion side of animals tested at this time should be the same as in animals tested 3-4 weeks postlesion. If, however, the ability to maintain extracellular DA continues to develop between $4 \mathrm{~d}$ and 3-4 weeks postlesion, the extracellular concentration of DA should be significantly higher in animals tested $3-4$ weeks postlesion than in animals tested $4 \mathrm{~d}$ postlesion. The latter result would suggest that the normalization of extracellular DA is relatively gradual, and can potentially account for the protracted time course of behavioral recovery.

\section{Materials and Methods}

Subjects and surgical procedures. Adult female rats (Holtzman SpragueDawley), weighing 200-250 gm, were housed individually in wire mesh cages in a room maintained on a 14:10 hr light:dark cycle (lights on at 0700 ), with free access to food and water. The animals were pretreated with $5 \mathrm{mg} / \mathrm{kg}$ atropine sulfate, anesthetized with $30 \mathrm{mg} / \mathrm{kg}$ sodium pentobarbital (i.p.) supplemented with methoxyflurane, and then mounted in a stereotaxic instrument. Twenty-one gauge stainless steel cannulas were then positioned on the dural surface, bilaterally, above each striatum [coordinatcs: $0.5 \mathrm{~mm}$ antcrior to bregma, $2.8 \mathrm{~mm}$ lateral, and 1.0 $\mathrm{mm}$ ventral from the surface of the skull, with bregma and lambda horizontal (Paxinos and Watson, 1986)]. In addition, a 23 gauge guide cannula was positioned on the dural surface above the rostral substantia nigra (coordinates: $5.0 \mathrm{~mm}$ posterior to bregma, $2.0 \mathrm{~mm}$ lateral, and $1.0 \mathrm{~mm}$ ventral from the surface of the skull). In half of the animals, this latter guide cannula was positioned in the left hemisphere and in the other half it was positioned in the right hemisphere. The guide cannulas were fixed in place with dental cement and jeweler's screws attached to the skull. Stainless steel stylets were used to maintain patency. At the completion of surgery and recovery from anaesthesia, the animals were returned to their home cages.

6-OHDA lesions. At least $2 \mathrm{~d}$ following surgery, the animals were divided into groups that were to receive either a 6-OHDA lesion or to serve as controls. Animals in both groups were pretreated with $15 \mathrm{mg} /$ $\mathrm{kg}$ desipramine- $\mathrm{HCl}$ (Breese and Traylor, 1971). Between 30 and 60 min later a 30 gauge injection cannula was inserted into the guide cannula overlying the substantia nigra, so that its tip was located 7.4 $\mathrm{mm}$ ventral from the surface of the skull. In the 6-OHDA group 1.5$8 \mu \mathrm{g}$ of $6-\mathrm{OHDA}-\mathrm{HBr}$ dissolved in $4 \mu \mathrm{l}$ of vehicle $(0.9 \% \mathrm{NaCl}$ solution containing $0.1 \mathrm{mg} / \mathrm{ml}$ ascorbic acid) was infused over a period of $8 \mathrm{~min}$, and the injection cannula was left in place for an additional $2 \mathrm{~min}$ before it was removed and the stylet replaced. In control rats, the injection cannula was inserted into the guide cannula, left in place for $10 \mathrm{~min}$, and then was removed. This day, the day of the lesion or sham lesion, was defined as day 0.

Microdialysis test procedure. Approximately half of the animals with a 6-OHDA lesion and half of the control animals underwent microdialysis on day 4 after the lesion, and the other half underwent microdialysis 3-4 weeks following the lesion. The day prior to the microdialysis test a dialysis probe was inserted into the guide cannula overlying each striatum, and was positioned so the 4-mm-long dialysis surface of the probe sampled the entire dorsoventral extent of the corpus of the striatum, as illustrated in Figure 4 of Robinson and Whishaw (1988) The dialysis probes and procedures have been described in detail previously (Robinson and Camp, 1991). Each rat was then placed into a hemispherical testing chamber equipped for both microdialysis and for the automated measurement of rotational behavior. The probes were perfused continuously with a perfusion solution containing $145 \mathrm{~mm}$ $\mathrm{NaCl}, 2.7 \mathrm{~mm} \mathrm{KCl}, 1.2 \mathrm{~mm} \mathrm{CaCl}, 1.0 \mathrm{~mm} \mathrm{MgCl}_{2}$, and $0.2 \mathrm{~mm}$ ascorbic acid, pH 7.3 (Moghaddam and Bunney, 1989), at a flow rate of $0.3 \mu \mathrm{l} /$ min. The following day the pump speed was increased to $1.5 \mu 1 / \mathrm{min}$, and after at least a $30 \mathrm{~min}$ equilibration period, a minimum of three $20 \mathrm{~min}$ basal samples of dialysate were collected. Following this, each rat received an intraperitoneal injection of $1.5 \mathrm{mg} / \mathrm{kg} d$-amphetamine sulfate (weight of the salt), and 10 additional $20 \mathrm{~min}$ samples of dialysate were collected. At the completion of the experiment the dialysis probes were removed, the stylets were replaced, and the rats were returned to their home cages. Dialysate was assayed with high-performance liquid chromatography and electrochemical detection (HPLC-EC) using procedures similar to those described by Robinson and Camp (1991). Al dialysis probes had been tested for recovery in vitro prior to use, and dialysate values reported here were corrected for recovery.

At the same time as dialysate was collected, rotational behavior was monitored using a device described by McFarlane et al. (1992), which was attached to the tether. This photocell device recorded the number of $90^{\circ}$ turns to the left and right during each $20 \mathrm{~min}$ interval. These data were converted to full rotations, which are defined as four consecutive $90^{\circ}$ turns in the same direction, and net rotations, which are defined as full rotations in the dominant direction minus full rotations in the nondominant direction.

Tissue assay. Between 1 and 2 months following the 6-OHDA lesion the animals were killed by decapitation and their brains removed and placed in ice-cold saline. After the brain cooled $(30-45 \mathrm{sec})$, it was placed in a chilled cutting block and brain slices were obtained as described by Heffner et al. (1980). The slices were immediately examined and the location of the tracks formed by the dialysis probes were reconstructed on coronal plates from a rat brain atlas (Paxinos and Watson, 1986). Then, using a $2 \mathrm{~mm}$ tissue punch, a sample from the corpus of each striatum was taken, weighed, and placed into separate tubes containing $0.05 \mathrm{~N}$ perchloric acid and dihydroxybenzylamine (internal standard). The samples were homogenized and centrifuged and the supernatant was assayed by HPLC-EC, using procedures similar to those described previously (Robinson et al., 1987).

\section{Results}

\section{Group assignment}

Data are included only for those animals with probes located in the corpus of the neostriatum. Also, complete data (c.g., basal chemistry, full amphetamine time course, behavior, etc.) were not always available for every individual animal because of occasional equipment malfunction or expcrimenter crror. Therefore, the final $N$ s for each group vary somewhat for different measures. Final $N$ s are indicated in the figure captions.

Animals with a 6-OHDA lesion were assigned to one of three 
subgroups on the basis of lesion size, and these groups were further subdivided into those animals tested $4 \mathrm{~d}$ and those animals tested 3-4 weeks postlesion. Lesion size was estimated by expressing the difference in DA content in postmortem tissue ( $\mathrm{pg} / \mathrm{mg}$ wet tissue weight) between the striatum on the intact side and lesion side, as a percentage of that on the intact side (intact - lesion/intact $\times 100$ ). Postmortem tissue DA concentrations are known to provide a good index of the degree of striatal DA denervation following a 6-OHDA lesion (Altar et al., 1987). The three subgroups consisted of animals with (1) a $20-80 \%$ lesion, (2) a $80-95 \%$ lesion, and (3) a $>95 \%$ lesion. Control animals were assigned a lesion size of zero. Figure 1 shows that there was no effect of time postlesion on average lesion size. Also note, however, that postmortem tissue values were not obtained for five animals in the $4 \mathrm{~d},>95 \%$ group. They were included in this group on the basis of an apomorphine screening test $(0.05 \mathrm{mg} / \mathrm{kg})$, and their data were also used in the report by Robinson et al. (1994).

\section{Basal concentrations of DA, DOPAC, HVA, and 5-HIAA in dialysate}

The mean ( \pm SEM) basal concentrations of DA, dihydroxyphenylacetic acid (DOPAC), homovanillic acid (HVA), and 5-hydroxyindoleacetic acid (5-HIAA) in dialysate in all groups are plotted as a function of lesion size in the four panels of Figure 2. The most important result is the effect of time postlesion on the basal concentration of DA in dialysate. This is shown in Figure $2 A$, which illustrates two critical findings. First, although basal DA was decreased as a function lesion size in both groups, the basal concentration of DA in dialysate was significantly higher in animals tested 3-4 weeks postlesion than in animals tested $4 \mathrm{~d}$ postlesion (see the figure captions for summaries of the statistical analyses). Second, despite an average lesion size of $54 \%$, rats with a $20-80 \%$ lesion tested $3-4$ weeks postlesion had a normal basal concentration of DA in dialysate, relative to controls. In contrast, there was a significant decrease in the basal concentration of DA in rats with a comparable lesion ( $52 \%$ ), but tested 4 d postlesion, relative to controls.

In Figure 2, $B$ and $C$ show that the basal concentrations of DOPAC and HVA in dialysate were also decreased as a function of lesion size in animals tested either $4 \mathrm{~d}$ or 3-4 weeks postlesion. But in contrast to DA, there was no significant effect of time postlesion (and no significant interaction) for either DOPAC or HVA.

Figure $2 D$ shows that there was no effect of time postlesion or lesion size on the basal concentration of 5-HIAA in dialysate.

\section{Fractional DA efflux}

The relative amount of basal DA efflux from residual DA terminals (i.c., relcase per terminal) was estimated by fractional DA efflux, which was calculated by dividing the concentration of DA in dialysate $(\mathrm{pg} / \mu \mathrm{l})$ by the DA content in postmortem tissue (pg/mg), and multiplying by 100 (Castañeda et al., 1990). Fractional DA efflux in animals tested $4 \mathrm{~d}$ or 3-4 weeks postlesion is plotted as a function of lesion size in Figure 3. There was a significant increase in fractional DA efflux in animals with a 6-OHDA lesion tested either $4 \mathrm{~d}$ or 3-4 weeks postlesion, relative to control animals with no lesion. What is more important here is that the magnitude of the increase in fractional DA efflux was significantly greater in animals tested $3-4$ weeks

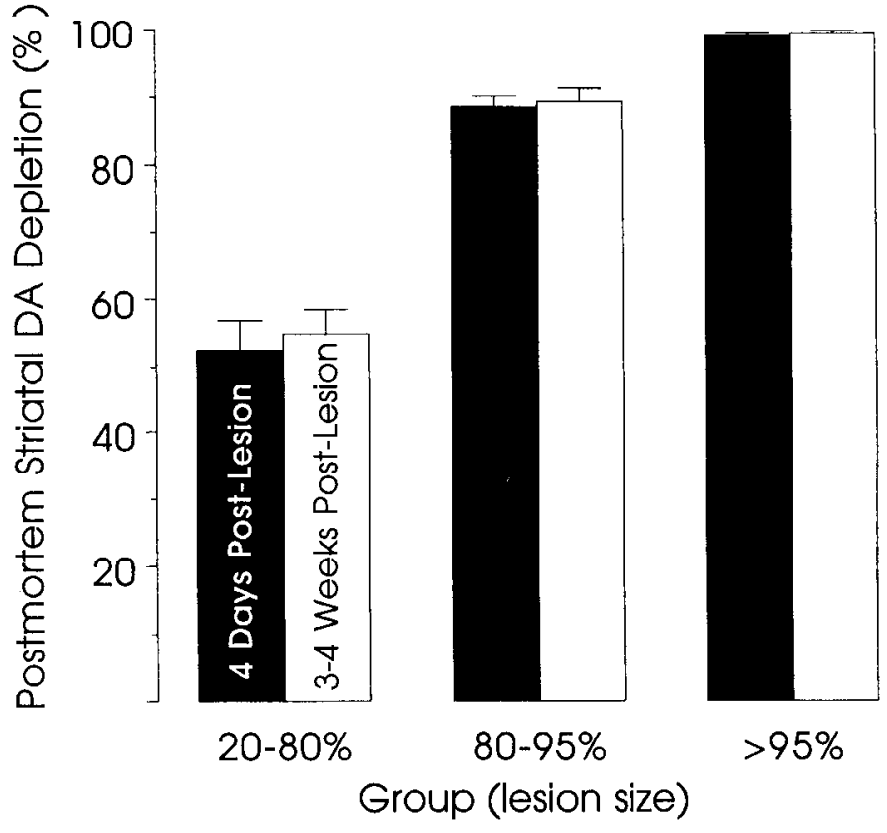

Figure 1. The postmortem tissue concentrations of DA in the striatum on the lesion side expressed as percentage depletion, relative to the striatum on the intact side, in each of the three subgroups tested either $4 \mathrm{~d}$ or $3-4$ weeks postlesion. The $N$ s for each group, proceeding left to right on the figure, are $14,19,9,8,8$, and 17 (see also Results). There was no effect of time postlesion on lesion size ( $t$ tests).

postlesion than in animals tested $4 \mathrm{~d}$ postlesion, regardless of lesion size.

\section{Amphetamine challenge}

Kotational behavior. Figure 4 shows that amphetamine had very different effects on rotational behavior as a function of time postlesion, and as a function of lesion size. When given amphetamine $4 \mathrm{~d}$ postlesion, all groups turned predominantly away from their lesion side (contraversive). Animals with a $20-80 \%$ lesion showed only low rates of contraversive rotation, and did not differ significantly from control. Animals with a $80-95 \%$ or a $>95 \%$ lesion showed more vigorous contraversive rotation, and differed significantly from control (but not from each other). Amphetamine produced a very different pattern of rotational behavior when given 3-4 weeks postlesion. At this time, all groups turned predominantly toward their lesion side (ipsiversive), although animals with a $20-80 \%$ or $80-95 \%$ lesion did not differ significantly from control. Animals with a $>95 \%$ lesion showed more vigorous ipsiversive rotation, and differed significantly from control, and from the other two lesion groups.

Dialysate. Figure 5 shows the effect of amphetamine on the concentration of DA in dialysate, plotted as a function of lesion size, in animals tested either $4 \mathrm{~d}$ postlesion $(A, B)$ or $3-4$ weeks postlesion $(C, D)$. In Figure $5, A$ and $C$ show dialysate DA concentrations in the striatum on the lesion side, whereas $B$ and $D$ show dialysate DA concentrations in the striatum on the intact side. In the intact striatum, amphetamine caused a large increase in the concentration of DA in dialysate in all groups. Amphetamine produced very different effects on the lesion side, however, both as a function of lesion size and time postlesion.

In animals with a $20-80 \%$ lesion, amphetamine produced a large increase in DA, both $4 \mathrm{~d}$ postlesion and 3-4 weeks postlesion, although the magnitude of the increase in DA was sig- 


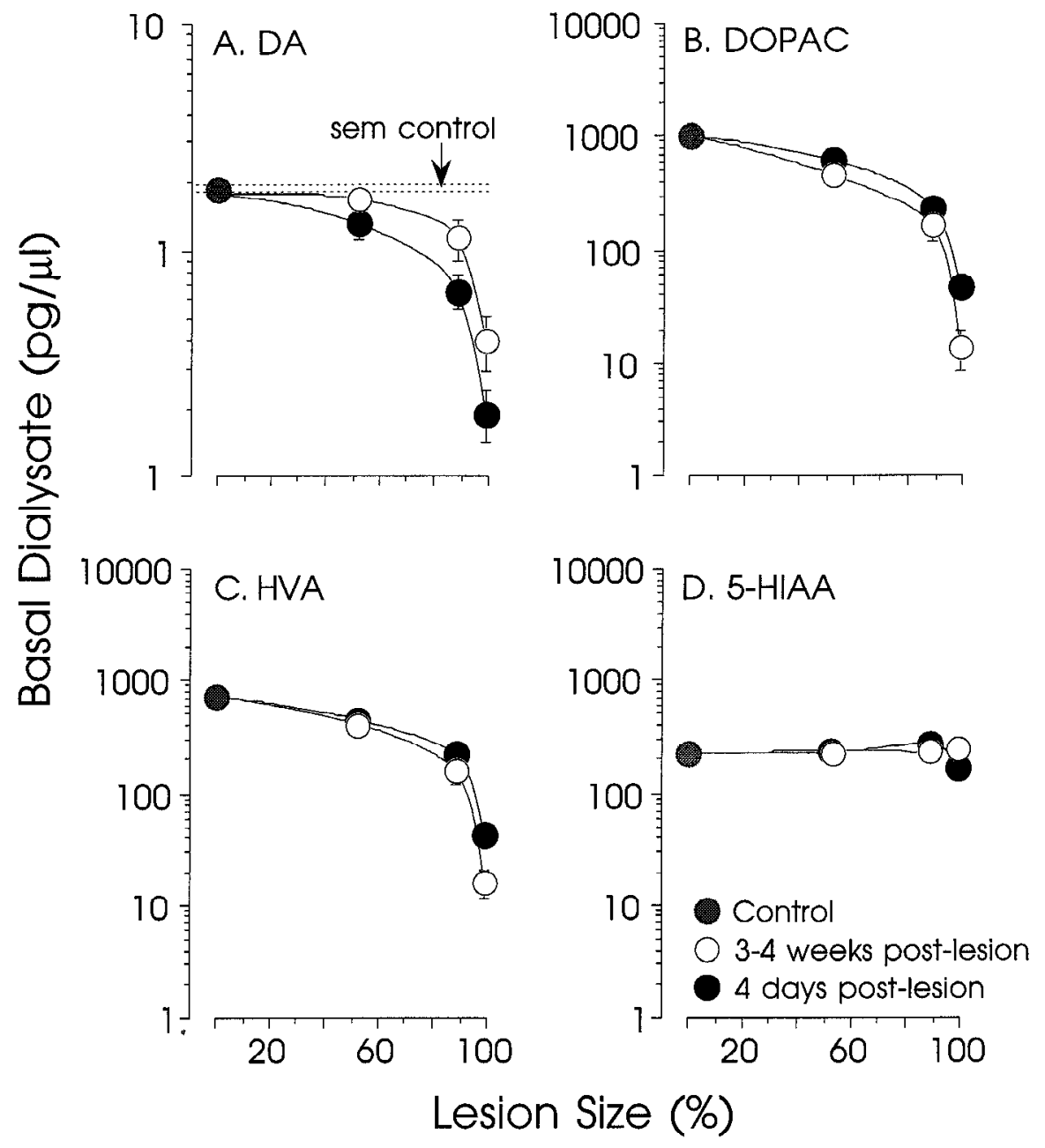

Figure 2. The mean ( \pm SEM) basal concentration of dopamine (DA; $A$ ), dihydroxyphenylacetic acid (DOPAC; $B$ ), homovanillic acid (HVA; $C$ ), and 5-hydroxyindoleacetic acid (5-IIAA; $D)$ in the striatum on the lesion side, plotted as a function of lesion size, in animals tested either $4 \mathrm{~d}$ (solid circles) or 3-4 weeks (open circles) following a unilateral 6-OHDA lesion. Values for control animals (shaded circles) with no lesion are indicated by a lesion size of zero. Note that dialysate concentrations are plotted on a log scale. If SEM bars are not visible they are smaller than the symbol. In $A$, the horizontal dashed lines represent \pm SEM of the control group. Summary of statistical analyses: $A$ (DA): two-way ANOVA comparing the $4 \mathrm{~d}$ and 3-4 week groups as a function of lesion size, effect of time postlesion, $F_{t}=7.02, p<0.01$; effect of lesion size, $F_{l}=33.7$, $p<0.0001$; time postlesion by lesion size interaction, $F_{i}=0.32$ (not significant, NS); in comparison to control (Fisher's PLSD tests following a significant one-way ANOVA), all values were significantly less than control (all $p \mathrm{~s}<0.02$ ), except the $3-4$ week group with a $20-80 \%$ lesion. $B$ (DOPAC): two-way ANOVA, $F_{t}=3.32, p<0.073$ (NS); $F_{t}=43.9, p<0.0001 ; F_{i}=0.63$ (NS); all values for lesion groups are significantly less than control (all $p \mathrm{~s}<0.0001$, Fisher's PLSD tests). $C$ (HVA): two-way ANOVA, $F_{t}=1.01$ (NS); $F_{i}=35.9, p<0.0001 ; F_{i}=0.06$ (NS); all values for lesion groups are significantly less than control (all $p \mathrm{~s}<0.0001$ ). $D\left(5\right.$-HIAA): $F_{t}=0.217$ (NS); $F_{t}=0.453$ (NS); $F_{i}=1.14$ (NS); no values for lesion groups are significantly less than control (all $p \mathrm{~s}>0.18) . N \mathrm{~s}=19$ (control), $14(4 \mathrm{~d}, 20-80 \%), 10(4 \mathrm{~d}, 80-95 \%), 13(4 \mathrm{~d},>95 \%), 17(3-4$ weeks, 20-80\%), 8 (3-4 weeks, 80-95\%), and 17 (3-4 weeks, >95\%).

nificantly less than in control animals. In animals with a 80 $95 \%$ lesion, amphetamine also produced a significant increase in DA in animals tested either $4 \mathrm{~d}$ or $3-4$ weeks postlesion, although the magnitude of the increase in DA was significantly less than in controls, and in animals with a $20-80 \%$ lesion. Furthermore, there was no significant effect of time postlesion on amphetamine-stimulated DA release in animals with a 20 $80 \%$ or $80-95 \%$ lesion. In contrast, there was a marked effect of time postlesion on amphetamine-stimulated DA release in animals with a $>95 \%$ lesion. When tested $4 \mathrm{~d}$ postlesion, these animals showed a relatively large increase in DA in response to amphetamine. In fact, at $4 \mathrm{~d}$ postlesion, animals with a $>95 \%$ lesion showed slightly greater amphetamine-stimulated DA release than animals with only an 80-95\% lesion (Fig. $5 A$; interaction significant, $p=0.006$ ). But by $3-4$ weeks postlesion, amphetamine produced only a very small change in DA, although it was still statistically significant.

Figure 6 shows the effects of amphetamine on the concentration of DOPAC and HVA in dialysate obtained from the lesion side, plotted as a function of lesion size and time postlesion. There was a large decrease in the basal concentration of both DOPAC and HVA (time zero sample), as a function of increasing lesion size, in animals tested at either $4 \mathrm{~d}$ (Fig. 6A,B) or 34 weeks postlesion (Fig. 6C,D). In control animals, in animals with a $20-80 \%$ lesion, and in animals with an $80-95 \%$ lesion, tested either $4 \mathrm{~d}$ or 3-4 weeks postlesion, amphetamine produced the expected decrease in the concentration of DOP $\Lambda \mathrm{C}$ and HVA in dialysate. In animals with a $>95 \%$ lesion tested 3-4 weeks postlesion, DOPAC and HVA were nondetectable in most instances. The only unexpected effect was in animals 


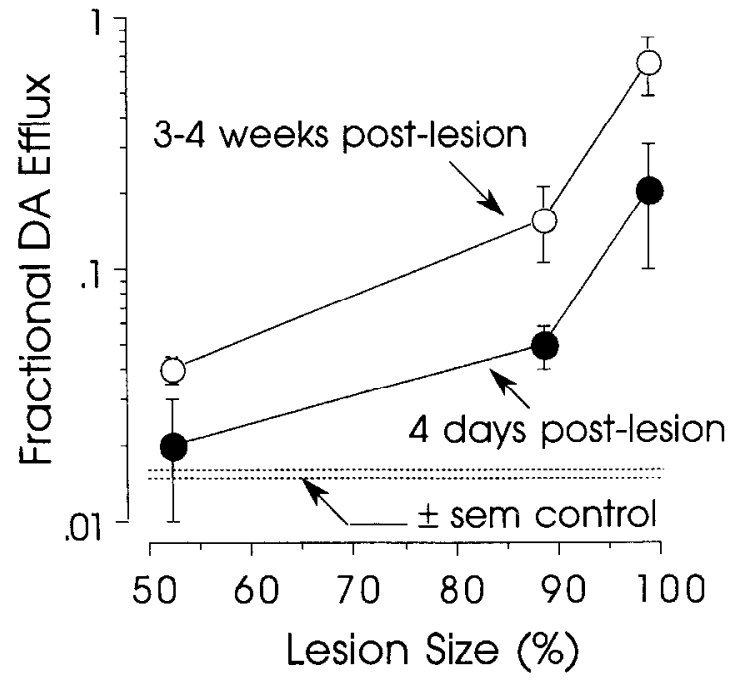

Figure 3. Mean $( \pm$ SEM) fractional DA efflux in the striatum on the lesion side, plotted as a function of lesion size, in animals tested either $4 \mathrm{~d}$ (solid circles) or 3-4 weeks (open circles) following a unilateral 6 -OHDA lesion. The horizontal dashed lines represent \pm SEM of the control group. Fractional DA efflux was significantly elevated in animals tested $4 \mathrm{~d}$ or 3-4 weeks following the lesion, relative to controls ( $p \mathrm{~s}<$ 0.05 , Mann-Whitney $U$ tests). However, fractional DA efflux was elevated significantly more in animals tested $3-4$ weeks postlesion than in animals tested 4 d postlesion (two-way ANOVA: $F_{t}=4.84, p<0.031$; $F_{l}=8.86, p<0.001 ;$ interaction not significant).

with a $>95 \%$ lesion tested $4 \mathrm{~d}$ postlesion. In these animals, amphetamine actually produced a significant increase in the concentration of both DOPAC and HVA in dialysate (Fig. $6 A, B$ ).

\section{Discussion}

The purpose of this experiment was to determine whether the normalization of extracellular DA seen in the striatum of animals with a partial 6-OHDA lesion is complete within a few days postlesion, or whether it continues to develop over a longer period of time. The results were clear: the concentration of DA in dialysate obtained from the striatum on the lesion side was significantly higher 3-4 weeks following a unilateral 6-OHDA lesion than $4 \mathrm{~d}$ postlesion, after equating for lesion size. This suggests that the compensatory normalization of extracellular DA that follows damage to the nigrostriatal DA system (Robinson et al., 1990a) is a relatively gradual process and therefore can potentially account for the protracted time course of behavioral recovery. It is known from previous studies that presynaptic adaptations leading to the normalization of extracellular DA are necessary for recovery of function (Stricker and Zigmond, 1976; Marshall, 1984). The data presented here suggest presynaptic adaptations also may be sufficient.

It is interesting to contrast the results of Altar et al. (1987) with those reported here. Altar et al. (1987) report that in postmortem striatal tissue, a number of indices of presynaptic activity are already maximal within $3 \mathrm{~d}$ following a partial unilateral 6-OHDA lesion. These include measures of DA metabolism (e.g., DOPAC:DA ratios), DA synthesis (DOPA accumulation after decarboxylase inhibition), and DA release (3-MT:DA ratios). Their data suggest, therefore, that presynaptic adaptations cannot account for the protracted time course of behavioral recovery. We suggest, however, that the normalization of extracellular DA may be more relevant for behavioral

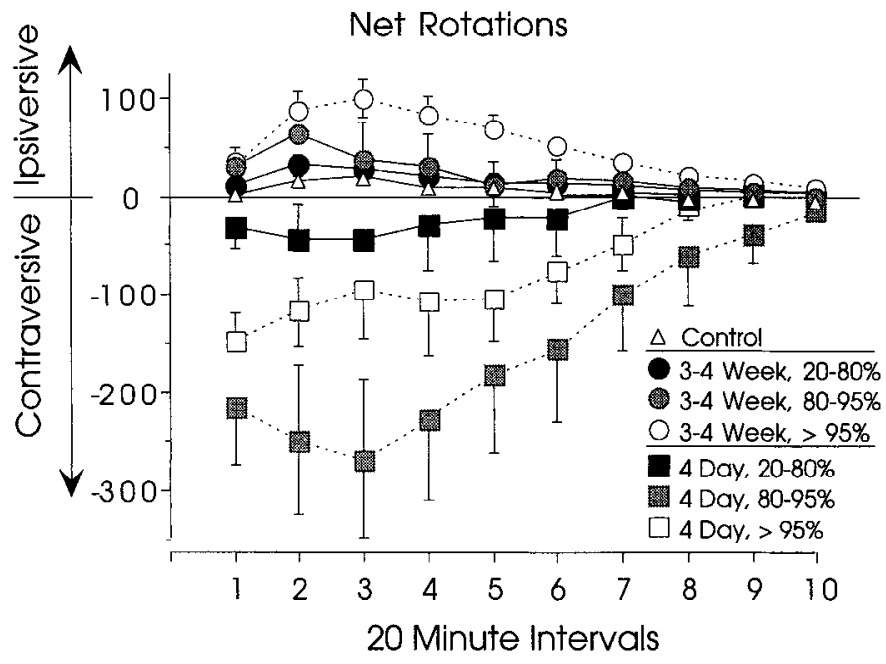

Figure 4. The mean $( \pm \mathrm{SEM})$ number of net rotations per $20 \mathrm{~min}$ interval induced by $1.5 \mathrm{mg} / \mathrm{kg} d$-amphetamine sulfate in animals undergoing microdialysis, and tested $4 \mathrm{~d}$ (squares) or 3-4 weeks (circles) following a unilateral 6-OHDA lesion. Animals with lesions are subdivided into three subgroups: those with a $20-80 \%$ lesion (solid symbols), those with an $80-95 \%$ lesion (shaded symbols), or those with a $>95 \%$ lesion (open symbols). Control animals $(N=10)$ are indicated by open triangles. Positive numbers were arbitrarily defined as ipsiversive rotations and negative numbers as contraversive rotations. Groups for which symbols are connected with a dashed rather than solid line differ significantly from control. Summary of statistical analyses. At day 4 postlesion, animals with a 6-OHDA lesion showed predominantly contraversive rotation, and there were significant group differences [twoway ANOVA, effect of lesion size, $F_{l}=4.9, p<0.004$; effect of time (amphetamine), $F_{t}=9.4, p<0.0001$; interaction, $\left.F_{i}=2.8, p<0.0001\right]$. Animals with a $20-80 \%$ lesion $(N=12)$ did not differ significantly from control, but animals with a $80-95 \%\left(N=10 ; F_{i}=9.19, p<0.01 ; F_{i}=\right.$ $5.98, p<0.0001)$ or a $>95 \%$ lesion $\left(N=12 ; F_{l}=8.52, p<0.01 ; F_{l}\right.$ $=4.34, p<0.0001$ ) showed significantly more vigorous rotation than control. The $20-80 \%$ lesion group differed from the $80-95 \%$ lesion group, but no other comparisons were significant (two-way ANOVAs). At 3-4 weeks postesion, all groups showed predominantly ipsiversive rotation, and there were significant group differences $\left(F_{l}=5.63, p=\right.$ $\left.0.002 ; F_{i}=3.34, p<0.0001\right)$. The group with a $>95 \%$ lesion $(N=15)$ differed from all other groups $\left(F_{i}=2.04-6.37, p \mathrm{~s}<0.04-0.0001\right)$, but no other comparisons were statistically significant $(20-80 \%, N=17$; $80-95 \%, N=6$ ).

recovery, and as summarized above, this is not complete within $4 \mathrm{~d}$ postlesion. Presumably, the adaptations in DA synthesis and metabolism described by Altar et al. (1987), and others (Stricker and Zigmond, 1986), contribute to the normalization of extracellular DA reported here. But the present study further demonstrates that the normalization of extracellular DA must involve additional processes as well (Parsons et al., 1991), which have a different time course than the compensatory changes in synthesis and metabolism measured in postmortem tissue.

Onc candidate process that may contribute to the more gradual normalization of extracellular DA is a lesion-associated change in the diffusibility of DA in the striatum. Under normal conditions, very little DA diffuses away from the synaptic cleft because there is a very efficient uptake system for DA (Ewing and Wightman, 1984). This presumably accounts for the very low extracellular concentration of DA measured with microdialysis, relative to that estimated to be in the synaptic cleft. Following a 6-OHDA lesion, however, there is a marked increase in the diffusibility of DA in the striatum (Doucet et al., 1986), presumably due to a decrease in the rate of DA clearance 


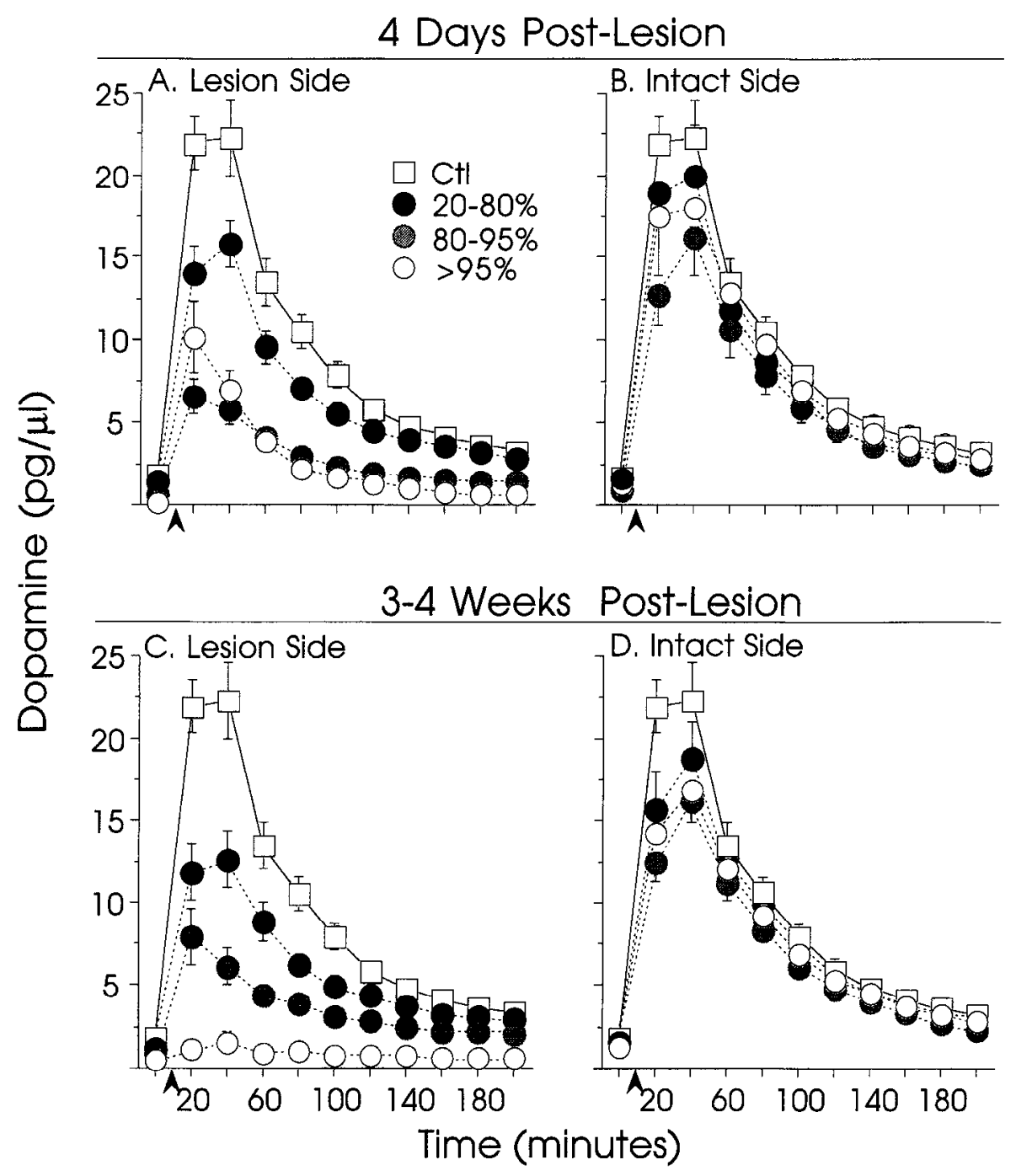

Figure 5. The mean ( \pm SEM) concentration of DA in dialysate $(\mathrm{pg} / \mu \mathrm{l})$ in $20 \mathrm{~min}$ intervals before (first interval, time zero) and following (subsequent intervals) $1.5 \mathrm{mg} / \mathrm{kg}$ of $d$-amphetamine in animals tested $4 \mathrm{~d}(A, B)$ or 3-4 weeks $(C, D)$ following a unilateral 6-OHDA lesion. Amphetamine was given where indicated by the arrowheads. $A$ and $C$ show dialysate values obtained from the striatum on the lesion side, and $B$ and $D$ show dialysate values on the intact side. Animals with lesions are subdivided into the three subgroups of varying lesion size, as described in Results. Control animals are indicated by open squares, and the same control values are plotted in $A-D$ for ease of comparison. The statistical analyses are summarized as follows. (1) Intact side, $4 \mathrm{~d}$ postlesion: amphetamine produced a significant increase in DA in all groups, and there was no effect of lesion size on amphetamine-stimulated DA release [two-way ANOVA, effect of lesion size, $F_{l}=1.45, p<0.241$; cffect of time (amphetamine), $F_{i}=141, p$ $<0.0001$; interaction, $F_{i}=1.17, p<0.251$ ]. (2) Intact side, $3-4$ weeks postlesion: amphetamine produced a significant increase in DA in all groups (all $p \mathrm{~s}<0.0001$ ), and there was a small decrease in the magnitude of amphetamine-stimulated DA release in the three lesion groups, relative to the control group (two-way ANOVAs, interaction effects significant, $p$ s $<0.01$ ). However, none of the lesion groups differ from one another (twoway ANOVAs). (3) Lesion side, $4 \mathrm{~d}$ postlesion: amphetamine produced a significant increase in DA in all groups (all $p s<0.0001$ ), but the amount of amphetamine-stimulated DA release was significantly decreased in all lesion groups, relative to the control group. All lesion groups differ significantly from one another, based on multiple two-way ANOVAs, following a significant overall two-way ANOVA; all interaction effect $p$ s < 0.001 . (4) Lesion side, 3-4 weeks postlesion: the statistical results were the same as for the lesion side, $4 \mathrm{~d}$ postlesion group above. In addition, there was no significant effect of time postlesion on amphetamine-stimulated DA release on the lesion side of animals with a $20-80 \%$ lesion $(F<$ $1.0)$, or $80-95 \%$ lesion $(F=1.18, p=0.29)$. There was, however, a significant decrease of amphetamine-stimulated DA release on the lesion side between $4 \mathrm{~d}$ and $3-4$ weeks postlesion in animals with a $>95 \%$ lesion $(F=15.7, p<0.001)$, although the very small amphetamine-induced increase in DA in this group was statistically significant (repeated-measures ANOVA, $F=4.11, p<0.0001) . N \mathrm{~s}=19$ (control), $11(4 \mathrm{~d}, 20-80 \%), 10(4$ d, 80-95\%), 12 (4 d, >95\%), 13 (3-4 weeks, 20-80\%), 8 (3-4 weeks, 80-95\%), and 16 (3-4 weeks, >95\%).

(Keller et al., 1988; Wightman and Zimmerman, 1990; van Horne et al., 1992). Thus, in animals with a 6-OHDA lesion, DA released from residual terminals is able to diffuse much farther than in intact animals (Doucet et al., 1986; Wightman and Zimmerman, 1990), and can presumably influence more distant targets. Although postmortem tissue measures of 3-MT may reflect an increase in DA release (Wood and Altar, 1988), they may not reflect this lesion-associated change in the diffu- sibility of DA. The extracellular concentration of DA, on the other hand, reflects the interaction of many factors (e.g., release, degradation, and clearance). The gradual normalization of extracellular DA may be due in part, therefore, to gradual changes in the diffusibility of DA.

A second process that may contribute to a gradual normalization of extracellular DA is a progressive increase in the amount of DA released per remaining terminal. In the present experi- 


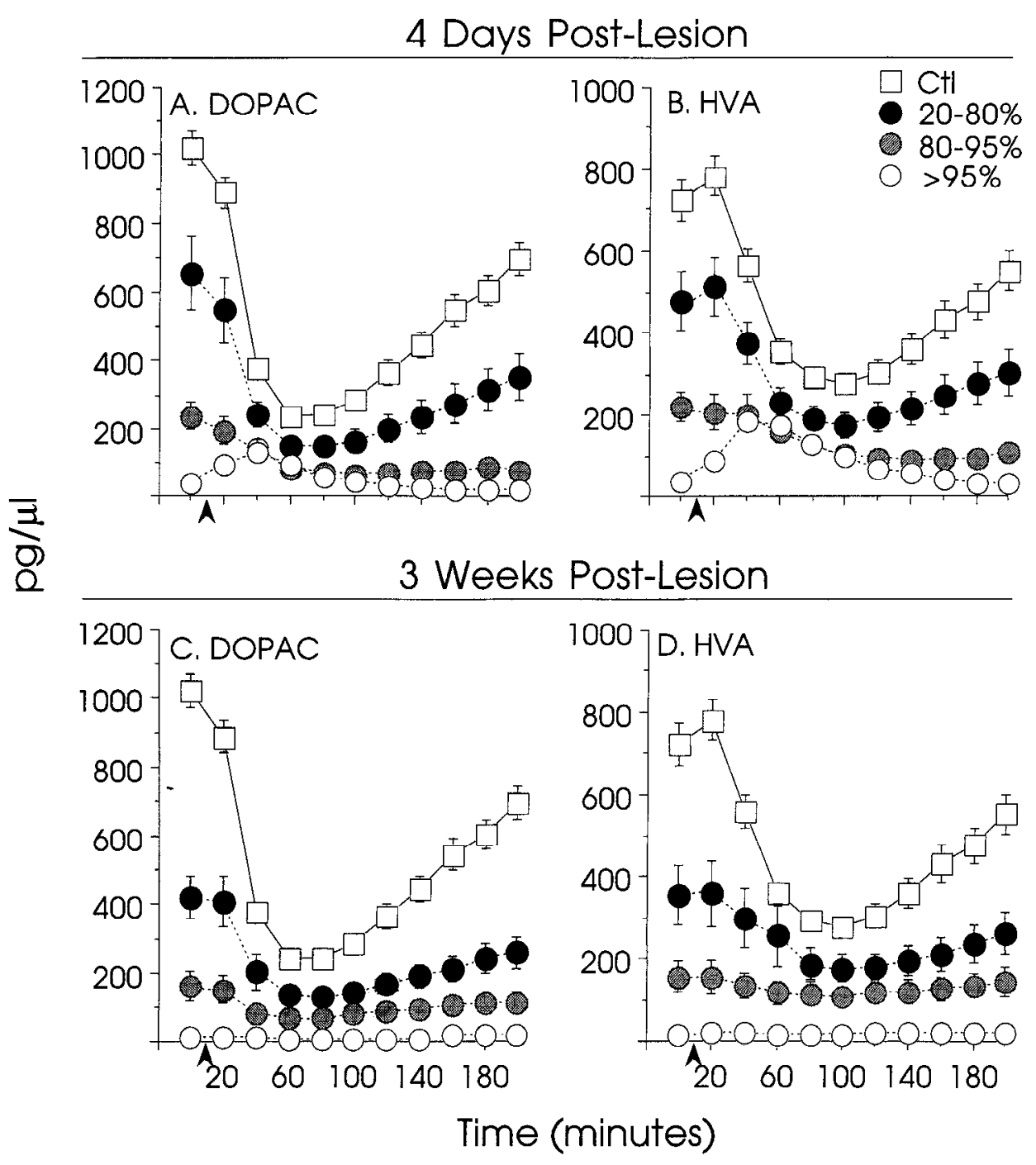

Figure 6. The mean $( \pm$ SEM) concentration of DOPAC $(A, C)$ and HVA $(B$, $D)$ in dialysate $(\mathrm{pg} / \mu \mathrm{l})$ obtained from the striatum on the lesion side in 20 min intervals, before (first interval, time zero) and following (subsequent intervals) $1.5 \mathrm{mg} / \mathrm{kg}$ of $d$-amphetamine, in animals tested $4 \mathrm{~d}(A, B)$ or 3-4 weeks $(C, D)$ following a unilateral 6-OHDA lesion. Amphetamine was given where indicated by the arrowheads. Animals with lesions are subdivided into the three subgroups of varying lesion size described in the text. Control animals are indicated by open squares. The same control values are plotted in $A$ and $C$, and in $B$ and $D$, for ease of comparison. Summary of statistical analyses is as follows. Within each of the four panels, all groups differ significantly from one another, based on multiple two-way ANOVAs, following a significant overall two-way ANOVA (all interaction effect $p$ s $<0.01-0.0001)$. In addition, on $4 \mathrm{~d}$ postlesion, and only in animals with a $>95 \%$ lesion, amphetamine produced a significant increase in both DOPAC and HVA (repeated-measures ANOVAs: DOPAC, $F=20.39, p<0.0001$; HVA, $F=16.4, p<0.0001) . N$ s are as for Figure 5 . ment this was estimated by fractional DA efflux. Although fractional DA efflux was already elevated $4 \mathrm{~d}$ postlesion, it increased significantly further by 3-4 weeks postlesion. Therefore, the interaction of a number of factors, including a time-dependant increase in fractional DA release and increasing diffusibility of DA, may lead to the relatively gradual normalization of extracellular DA reported here.

Some of the changes in amphetamine-induced rotational behavior between $4 \mathrm{~d}$ and $3-4$ weeks postlesion also suggest that the nigrostriatal DA system continues to adapt over this period of time. For example, when given amphetamine $4 \mathrm{~d}$ postlesion, animals turned contralateral to their lesion side, that is, opposite the normal direction (Ungerstedt, 1971a,b; Pycock, 1980). Indeed, there are a number of reports of contraversivc rotation to amphetamine for a number of days following a unilateral 6-OHDA lesion (Ungerstedt, 1971 b; Mintz et al., 1986; Lynch and Carey, 1989; Carey, 1992; Robinson et al., 1993). After about $6 \mathrm{~d}$, animals switch direction and show ipsiversive rotation to amphetamine (Carey, 1992; Robinson et al., 1994), as also seen in animals tested 3-4 weeks postlesion here.

At first glace, the contraversive rolation described here seems to contradict a basic tenet of the rotational behavior model, which is that animals turn away from the more active striatum (Ungerstedt, 1971a,b), because animals turned toward the stria- tum showing the greatest amphetamine-stimulated DA release, that is, the intact striatum. On the other hand, amphetaminestimulated DA release was not abolished on the lesion side $4 \mathrm{~d}$ postlesion, even in rats with a $>95 \%$ lesion. In fact, amphetamine produced a sizable increase in extracellular DA on the lesion side at this time. We suggest, therefore, that even though amphetamine-stimulated DA release is attenuated on the lesion side, the DA that is released interacts with supersensitive DA receptors, resulting in greater postsynaptic activation on the lesion side than on the intact side (where DA acts on normosensitive receptors). The outcome is contraversive rotation (Robinson et al., 1994). That DA receptor supersensitivity is present $4 \mathrm{~d}$ postlesion is suggested by reports that animals are behaviorally hypersensitive to DA reccptor agonists within 2$3 \mathrm{~d}$ after a 6-OHDA lesion (Ungerstedt, 1971b; Costall et al., 1976; Staunton et al., 1981; Neve et al., 1982), and in vivo ${ }^{3} \mathrm{H}$ spiroperidol binding is significantly elevated within $4 \mathrm{~d}$ postlesion (Neve et al., 1982).

But why did animals not show contraversive rotation when given amphetamine 3-4 weeks postlesion? This is relatively easy to explain for rats with a $>95 \%$ lesion. By 3-4 weeks postlesion amphetamine produced almost no DA release on the lesion side of rats with a $>95 \%$ lesion. Receptor supersensitivity is not manifest in the absence of the ligand, so these animals turned 
away from the side that released DA-the intact side. But animals with a $80-95 \%$ lesion also stopped showing contraversive rotation between $4 \mathrm{~d}$ and 3-4 weeks postlesion, and by 3-4 weeks showed no significant rotational bias. This is more difficult to explain, because presumably these animals also developed DA receptor supersensitivity within $4 \mathrm{~d}$ postlesion, which is why they showed contraversive rotation at this time (i.e., for the same reason as the $>95 \%$ group). But unlike the $>95 \%$ group, amphetamine still produced a relatively large increase in DA release on the lesion side of rats with a $80-95 \%$ lesion 3-4 weeks postlesion. Why did this extracellular $D A$ not produce contraversive rotation 3-4 weeks postlesion, when apparently it did 4 d postlesion?

One possibility is that DA receptor sensitivity decreased between $4 \mathrm{~d}$ and 3-4 weeks postlesion in this group. A reason this might occur is shown in Figure 2. Between $4 \mathrm{~d}$ and 3-4 weeks postlesion there was a significant increase in the basal extracellular concentration of DA, as estimated by microdialysis. A tonic increase in synaptic DA could potentially downregulate DA receptors. In support of this hypothesis, Curran ct al. (1993) recently reported that a moderate increase in extracellular DA produced by a behaviorally effective adrenal graft was highly correlated with the restoration of symmetry in striatal DA $D_{2}$ receptor binding and behavior. We hypothesize, therefore, that in rats with an $80-95 \%$ lesion tested 3-4 weeks postlesion, the balance between the asymmetry in amphetamine-stimulated DA release (which favors the intact side) and DA receptor sensitivity (which may still slightly favor the lesion side) results in only a weak rotational bias. Although there was also an increase in basal DA in rats with a $>95 \%$ lesion between $4 \mathrm{~d}$ and 3-4 weeks postlesion, presumably this was not sufficient to downregulate DA receptors, because the absolute level of extracellular DA was far less in this group than in the $80-95 \%$ group.

The source of the amphetamine-releasable DA pool present on day 4 in rats with a $>95 \%$ lesion is unknown. There is considerable evidence that in these animals the striatum is already denervated of $90-95 \%$ of its DA input within 3-4 days postlesion, because by this time there is (1) a $90-95 \%$ decrease in the basal concentration of DOPAC in dialysate (Robinson et al., 1994; present study), (2) a $>90 \%$ decrease in the postmortem tissue concentration of DA (Staunton et al., 1981; Neve et al., 1982; Altar et al., 1984; Carey, 1992; Robinson et al., 1994), (3) a $>90 \%$ decrease in DA uptake sites (Altar et al., 1987), (4) a $>90 \%$ loss of DA histofluorescence (Hökfelt and Ungerstedt, 1973), and (5) an almost complete loss of boutons with small granular vesicles (Hökfelt and Ungerstedt, 1973). It is a transient pool, because by $8 \mathrm{~d}$ postlesion, amphetamine no longer induces $\mathrm{DA}$ release on the lesion side, and rats now turn in the ipsiversive direction (Carey, 1992; Robinson et al., 1994). Also, it does not seem to be a renewable pool, because it is exhausted by a single injection of amphetamine (Robinson et al., 1994). Robinson et al. (1994) have suggested this pool of DA may be located in a small number of striatal DA terminals that have not yet completely degenerated, which could correspond to boutons of the dense type described by Hökfelt and Ungerstedt (1969). If these terminals are isolated from their cell bodies they would receive no action potentials, which would explain why this pool does not seem to be mobilized by environmental stimuli that are thought normally to induce DA release (Mintz et al., 1986), and why spontaneous rotation is in the ipsiversive direction 4 d postlesion (Carey, 1992; Robinson et al., 1994).

Finally, one other unexpected observation that deserves men- tion is the amphetamine-induced increase in DOPAC and HVA seen in animals with a $>95 \%$ lesion tested $4 \mathrm{~d}$ postlesion. This effect was also observed recently by Robinson et al. (1994). Typically, amphetamine causes a large decrease in extracellular DOPAC and HVA (Kuczenski, 1983), as seen here in all the other groups. The decrease in DOPAC produced by amphetamine is thought to be due to an amphetamine-induced depletion of a cytoplasmic pool of DA that serves as the substrate for intraneuronal monoamine oxidase (MAO). The amount of DOPAC formed from DA that is released, taken back up, and then degraded by MAO, is thought to be insignificant, relative to the pool formed intraneuronally independent of release (Zetterström et al., 1988; Kuczenski and Segal, 1989). But by $4 \mathrm{~d}$ postlesion, animals with a $>95 \%$ lesion have lost $90-95 \%$ of this intraneuronal pool of DA (see above), although they still show considerable amphetamine-stimulated DA release. Presumably, the increase in DOPAC and HVA reflects the metabolism of this DA, which is unmasked because it now represents a relatively large amount of the DA available to MAO.

In summary, the most important finding reported here is that the basal concentration of DA in striatal dialysate on the side of a unilateral 6-OHDA lesion is significantly higher 3-4 weeks following the lesion than it is $4 \mathrm{~d}$ following the lesion. This establishes that the compensatory normalization of extracellular DA that occurs following partial damage to the nigrostriatal DA system is not complete within $4 \mathrm{~d}$, unlike some other presynaptic adaptations, and may be a relatively gradual process. We conclude, therefore, that the normalization of extracellular DA can potentially account for the protracted time course of behavioral recovery. It is known from previous studies that the presynaptic compensatory adaptations that follow partial damage to the nigrostriatal DA system are necessary for behavioral recovery (Stricker and Zigmond, 1976; Marshall, 1984). The results reported here suggest presynaptic adaptations may be also sufficient.

\section{References}

Abercrombie ED, Bonatz AE, Zigmond MJ (1990) Effects of L-dopa on extracellular dopamine in striatum of normal and 6-hydroxydopamine-treated rats. Brain Res 525:36-44.

Altar CA, O'Neil S, Marshall JF (1984) Sensorimotor impairment and elevated levels of dopamine metabolites in the neostriatum occur rapidly after intranigral injection of 6-hydroxydopamine or gammahydroxybutyrate in awake rats. Neuropharmacology 23:309-318.

Altar CA, Marien MR, Marshall JF (1987) Time course of adaptations in dopamine biosynthesis, metabolism, and release following nigrostriatal lesions: implications for behavioral recovery from brain injury. J Neurochem 48:390-399.

Breese GR, Traylor TD (1971) Depletion of brain noradrenaline and dopamine by 6-hydroxydopamine. Br J Pharmacol 42:88-99.

Carey RJ (1992) Factors in amphetamine-induced contralateral rotation in the unilateral 6-OHDA lesion rat model during the firstweek postoperative: implications for neuropathology and neural grafting. Brain Res 570:11-20.

Castañeda E, Whishaw IQ, Robinson TE (1990) Changes in striatal dopamine neurotransmission assessed with microdialysis following recovery from a bilateral 6-OHDA lesion: variation as a function of lesion size. J Neurosci 10:1847-1854.

Commissiong JW (1985) Monoamine metabolites: their relationship and lack of relationship to monoaminergic neuronal activity. Biochem Pharmacol 34:1127-1131.

Costall B, Marsden CD, Naylor R J, Pycock CJ (1976) The relationship between striatal and mesolimbic dopamine dysfunction and the nature of circling responses following 6-hydroxydopamine and electrolytic lesions of the ascending dopamine systems of rat brain. Brain Res 118:87-113. 
Creese I, Burt DR, Snyder SH (1977) Dopamine receptor binding enhancement accompanies lesion-induced behavioral supersensitivity. Science 197:596-598.

Curran EJ, Albin RL, Becker JB (1993) Adrenal medulla grafts in the hemiparkinsonian rat: profile of behavioral recovery predicts restoration of symmetry between the two striata in measures of pre- and postsynaptic dopamine function. J Neurosci 13:3864-3877.

Doucet G, Descarries L, Garcia S (1986) Quantification of the dopamine innervation in adult rat neostriatum. Neuroscience 19:427445.

Ewing AG, Wightman RM (1984) Monitoring the stimulated release of dopamine with in vivo voltammetry. II: Clearance of released dopamine from extracellular fluid. I Neurochem 43:570-577.

Heffner TG, Hartman JA, Seiden LS (1980) A rapid method for the regional dissection of the rat brain. Pharmacol Biochem Behav 13: $453-456$.

Hökfelt T, Ungerstedt U (1969) Electron and fluorescence microscopical studies on the nucleus caudatus putamen of the rat after unilateral lesions of ascending nigro-neostriatal dopamine neurons. Acta Physiol Scand 76:415-426.

Hökfelt T, Ungerstedt U (1973) Specificity of 6-hydroxydopamine induced degeneration of central monoamine neurones: an electron and fluorescence microscopic study with special reference to intracerebral injection on the nigro-striatal dopamine system. Brain Res 60:269-297

Keller RW Jr, Kuhr WG, Wightman RM, Zigmond MJ (1988) The effect of L-dopa on in vivo dopamine release from nigrostriatal bundle neurons. Brain Res 447:191-194.

Kuczenski R (1983) Biochemical actions of amphetamine and other stimulants. In: Stimulants: neurochemical, behavioral and clinical perspectives (Creese, I, ed), pp 31-61. New York: Raven.

Kuczenski R, Segal D (1989) Concomitant characterization of behavioral and striatal neurotransmitter response to amphetamine using in vivo microdialysis. J Neurosci 9:2051-2065.

Lees GJ, Kydd RR, Wright JJ (1985) Relationship between sensorimotor neglect and the specificity, degree and locus of mesotelencephalic dopaminergic cell loss following 6-hydroxydopamine. Psychopharmacology (Berlin) 85:115-122.

Lynch MR, Carey RJ (1989) Amphetamine-induced rotation reveals post 6-OHDA lesion neurochemical reorganization. Behav Brain Res 32:69-74

Marshall JF (1979) Somatosensory inattention after dopamine-depleting intracerebral 6-OHDA injections: spontaneous recovery and pharmacological control. Brain Res 177:311-324.

Marshall JF (1984) Brain function: neural adaptations and recovery from injury. Annu Rev Psychol 35:277-308.

Marshall JF (1985) Neural plasticity and recovery of function after brain injury. Int Rev Neurobiol 26:201-247.

Marshall JF, Richardson JS, Teitelbaum P (1974) Nigrostriatal bundle damage and the lateral hypothalamic syndrome. J Comp Physiol Psychol 87:808-830.

McFarlane DK, Martonyi BJ, Robinson TE (1992) An inexpensive automated system for the measurement of rotational behavior in small animals. Behav Res Method Instrument Comput 24:414-419.

Menacherry S, Hubert W, Justice JB Jr (1992) In vivo calibration of microdialysis probes for exogenous compounds. Anal Chem 64:577583.

Mintz M, Douglas RJ, Tomer R, de Villiers AS, Kellaway L (1986) Transient contralateral rotation following unilateral substantia nigra lesion reflects susceptibility of the nigrostriatal system to exhaustion by amphetamine. Life Sci 39:69-76.

Mishra RK, Gardner EL, Katzman R, Makman MH (1974) Enhancement of dopamine-stimulated adenylate cyclase activity in rat caudate after lesions in substantia nigra: evidence for denervation supersensitivity. Proc Natl Acad Sci USA 71:3883-3887.

Moghaddam B, Bunney BS (1989) Ionic composition of microdialysis perfusing solution alters the pharmacological responsiveness and basal outflow of striatal dopamine. J Neurochem 53:652-654.

Neve KA, Kozlowski MR, Marshall JF (1982) Plasticity of neostriatal dopamine receptors after nigrostriatal injury: relationship to recovery of sensorimotor functions and behavioral supersensitivity. Brain Res 244:33-44

Nieoullon A, Cheramy A, Glowinski J (1977) Interdependence of the nigrostriatal dopaminergic systems on the two sides of the brain in the cat. Science 198:416-418.
Parsons LH, Smith AD, Justice JB Jr (1991) The in vivo microdialysis recovery of dopamine is altered independently of basal level by 6-hydroxydopamine lesions to the nucleus accumbens. J Neurosci Methods 40:139-147.

Paxinos G, Watson C (1986) The rat brain in stereotaxic coordinates. New York: Raven.

Pycock CJ (1980) Turning behaviour in animals. Neuroscience 5:461514.

Robinson TE, Camp DM (1991) The feasibility of repeated microdialysis for within-subjects design experiments: studies on the mesostriatal dopamine system. In: Microdialysis in the neurosciences (Robinson TE, Justice JB Jr, eds), pp 189-234. Amsterdam: Elsevier.

Robinson TE, Whishaw IQ (1988) Normalization of extracellular dopamine in striatum following recovery from a partial unilateral 6-OHDA lesion of the substantia nigra: a microdialysis study in freely moving rat. Brain Res 450:209-224.

Robinson TE, Becker JB, Young EA, Akil H, Castañeda E (1987) The effects of footshock stress on regional brain dopamine metabolism and pituitary beta-endorphin release in rats previously sensitized to amphetamine. Neuropharmacology 26:679-691.

Robinson TE, Castañeda E, Whishaw IQ (1990a) Compensatory changes in striatal dopamine neurons following recovery from injury induced by 6-OHDA or methamphetamine: a review of evidence from microdialysis studies. Can J Psychol 44:253-275.

Robinson TE, Yew J, Paulson PE, Camp DM (1990b) The long-term effects of neurotoxic doses of methamphetamine on the extracellular concentration of dopamine measured with microdialysis in striatum. Neurosci Lett 110:193-198.

Robinson TE, Noordhoorn M, Chan EM, Mocsary Z, Camp DM, Whishaw IQ (1994) The relationship between asymmetries in striatal dopamine release and the direction of amphetamine-induced rotation during the first week following a unilateral 6-OHDA lesion of the substantia nigra. Synapse, in press.

Staunton DA, Wolfe BB, Groves PM, Molinoff PB (1981) Dopamine receptor changes following destruction of the nigrostriatal pathway: lack of a relationship to rotational behavior. Brain Res 211:315-327.

Stricker EM, Zigmond MJ (1974) Effects on homeostasis of intraventricular injections of 6-hydroxydopamine in rats. J Comp Physiol Psychol 86:973-394.

Stricker EM, Zigmond MJ (1976) Recovery of function after damage of central catecholamine-containing neurons: a neurochemical model for the lateral hypothalamic syndrome. In: Progress in psychobiology and physiological psychology, Vol 6 (Sprague JM, Epstein A, eds), pp 121-187. New York: Academic

Stricker EM, Zigmond MJ (1986) Brain monoamines, homeostasis, and adaptive behavior. In: Handbook of physiology, Vol 4, Intrinsic regulatory systems of the brain, pp 677-698. Bethesda, MD: American Physiological Society.

Touchet N, Bennett JJ (1989) The metabolism of systemically-administered L-dihydroxyphenylalanine, by intact and dopamine-denervated striata, as revealed by brain microdialysis. Neuropharmacology 28:1217-1222.

Ungerstedt U (1971a) Striatal dopamine release after amphetamine or nerve degeneration revealed by rotational behaviour. Acta Physiol Scand [Suppl] 367:49-68.

Ungerstedt U (1971b) Postsynaptic supersensitivity after 6-hydroxydopamine induced degeneration of the nigro-striatal dopamine system. Acta Physiol Scand [Suppl] 367:69-93.

Ungerstedt U, Hallström A (1987) In vivo microdialysis-a new approach to the analysis of neurotransmitters in the brain. Life Sci 41: 861-864.

van Horne C, Hoffer BJ, Stromberg I, Gerhardt GA (1992) Clearance and diffusion of locally applied dopamine in normal and 6-hydroxydopamine-lesioned rat striatum. J Pharmacol Exp Ther 263:1285-1292.

Wightman RM, Zimmerman JB (1990) Control of dopamine extracellular concentration in rat striatum by impulse flow and uptake. Brain Res Rev 15:135-144.

Wood PL, Altar CA (1988) Dopamine release in vivo from nigrostriatal, mesolimbic, and mesocortical neurons: utility of 3-methoxytyramine measurements. Pharmacol Rev 40:163-187.

Zetterström T, Sharp T, Collin AK, Ungerstedt U (1988) In vivo measurement of extracellular dopamine and DOPAC in rat striatum after various dopamine-releasing drugs; implications for the origin of extracellular DOPAC. Eur J Pharmacol 148:327-334. 
Zhang WQ, Tilson HA, Nanry KP, Hudson PM, Hong JS, Stachowiak MK (1988) Increased dopamine release from striata of rats after unilateral nigrostriatal bundle damage. Brain Res 461:335-342.

Zigmond MJ, Stricker EM (1973) Recovery of feeding and drinking by rats after intraventricular 6-hydroxydopamine or lateral hypothalamic lesions. Science 182:717-720.
Zigmond MJ, Abercrombie ED, Berger TW, Grace AA, Stricker EM (1990) Compensations after lesions of central dopaminergic neurons: some clinical and basic implications. Trends Neurosci 13:290-296. 